study, such as particle size, shape and surface chemistry, more than half were missing from 14 of the animal studies ${ }^{1}$.

Yongping Bao of the University of East Anglia in Norwich, UK, an author on one of the studies ${ }^{2}$ given low marks by Cantox, points out that some of the missing data appear in other papers by his group. But he believes that the review highlights the need for government regulatory agencies to establish agreed standards for this sort of research. "Anyone can set his or her own criteria to review nanotoxicity literature, so a gold standard is urgently needed," he says. Nanotoxicity studies arguably require additional standards, because nanoparticles can vary within a batch much more widely than do bulk chemicals, for example.

Altaf Carim, assistant director of nanotechnology at the White House Office of Science and Technology Policy, says that the US National Nanotechnology Initiative's Environmental, Health, and Safety Research Strategy ${ }^{3}$, unveiled in October, will develop a set of standards that should help researchers and agencies to plug that gap. "We are certainly hoping the broader community is going to make use of it," Carim says.

Nanotoxicologists have also lacked standard reference materials for defining nanoparticles. The US National Institute of Standards and Technology has produced references for gold and polystyrene nanoparticles, but has yet to issue similar samples of other nanomaterials.

Later this month, however, the institute will release its first batch of standard reference carbon nanotubes - the result of three years' work, according to Kalman Migler, who is overseeing the project. Researchers will be able to buy vials of the nanotubes to calibrate their measurement equipment and assess levels of common contaminants in their samples. The reference nanotubes, the first ever provided by a national standards agency, should help nanotoxicologists to pinpoint whether any observed adverse reactions are the result of nanoparticles rather than impurities, for example.

Yet the latest nanotechnology decree from Europe perhaps shows how far regulation efforts still have to go. On 18 October, the European Commission finally adopted a definition of a nanomaterial: one in which half or more of the particles in a sample have one dimension that measures between 1 and 100 nanometres ${ }^{4}$. The definition had been requested by the European Parliament in April 2009.

1. Card, J. W., Jonaitis, T. S., Tafazoli, S. \& Magnuson, B. A. Crit. Rev. Toxicol. 41, 20-49 (2011).

2. Zhang, J.-S., Gao, X.-Y., Zhang, L.-D. \& Bao, Y.-P. BioFactors 15, 27-38 (2001).

3. NNI Environmental, Health, and Safety Research Strategy (US Natl Sci. Technol. Council, 2011); available at http://go.nature.com/8hkuv3

4. Potočnik, J. Official J. EU L275/38-L275/40 (2011).

\title{
Novartis to shut brain research facility
}

\section{Drug giant redirects psychiatric efforts to genetics.}

\section{BY ALISON ABBOTT}

$\mathrm{N}$ ovartis has joined other pharmaceutical companies in abandoning traditional drug-discovery programmes that pursue treatments for brain disorders.

Nature has learned that the company is closing its neuroscience facility in Basel, Switzerland, where Novartis is headquartered.

It follows similar moves by GlaxoSmithKline and AstraZeneca, both based in the United Kingdom, which last year announced the closure of all their neuroscience research divisions globally. US-based companies Pfizer and Merck, as well as the French company Sanofi, have also pulled back on research into brain disorders. Rather than abandon neuroscience, however, Novartis says it will launch new programmes to study the genetics of psychiatric and cognitive disorders, in the hope of identifying new treatment strategies.

Developing drugs for brain disorders has become a high-risk activity, with most candidates failing after years of expensive clinical trials. The market is already flooded with cheap, generic antidepressants, antipsychotics and other drugs that act on known targets in the brain, mostly neurotransmitter receptors (see 'Mental-health drug sales'). This has forced companies to look for radically new drug targets, but the search is proving difficult because little is known about the biology of the brain and its disorders.

"Standard approaches to developing drugs for mental health have not reaped significant benefit in the past two decades," says Ken Kaitin, director of the Tufts Center for the Study of Drug Development in Boston, Massachusetts. "But it is a dilemma for the companies because there is a large and growing market for these products." Mental disorders impose the largest disease burden worldwide (see Nature

\section{MENTAL-HEALTH DRUG SALES}

Treatments for brain disorders represented a huge market for the pharmaceutical industry in 2010.

$\begin{array}{ll}\text { Antipsychotics } & \text { Antidepressants } \\ \mathbf{\$ 2 2} \text { bn } & \$ 20 \text { bn }\end{array}$

$\$ 22$ b $\$ 20$ bn
478, 15; 2011), and current treatments do not work particularly well for most patients.

The Basel neuroscience department has 80 staff, and five candidate drugs in the pipeline that act on the central nervous system (CNS). These drugs will continue to be developed, says geneticist Mark Fishman, president of research for the company's main research arm, the Novartis Institutes of BioMedical Research (NIBR). Novartis is negotiating with unions over the terms of the closure, which is likely to happen during 2012.

Fishman says that the NIBR will open a new research division to study the genetics of psychiatry and cognitive disorders at its site in Cambridge, Massachusetts, taking advantage "Developing of academic strength Developing in the area, including drugs for the brain has become highrisk, with most candidates failing." the Broad Institute, run jointly by Harvard University and the Massachusetts Institute of Technology, which has both major DNAsequencing capacity and a large group dedicated to psychiatric genetics. "Progress based on neurotransmitters has become small and incremental," Fishman told Nature. "Genetic analysis will provide a real scientific opportunity in psychiatric and cognitive disorders, even if new drugs only arrive in the distant future."

Recent population-based, genome-wide association studies have identified many different genetic variants that individually confer tiny increased risk of disease, but which may act together to substantially increase a person's susceptibility. A type of defect known as copy number variation, in which large chunks of DNA are gained or lost, may on its own cause a significant increase in risk for psychiatric disease. Scientists hope that understanding the

L 
- biological function of these risk genes may yield new clues about how to prevent or treat diseases.

Companies also hope that they will be able to find genetic biomarkers - a particular DNA sequence or variation, for example - that will allow them to identify individuals who are likely to respond to a particular drug, says Kaitin. "It's the basis of personalized medicine - health plans are more likely to pay for a new drug if they are convinced it will work for the person it is prescribed for."

Stephen Stahl, a psychopharmacologist and psychiatrist at the University of California, San Diego, says that other companies are also using gene sequencing to look for new targets. "GlaxoSmithKline pulled out of traditional CNS pharmacology but is pursuing research into neurodegeneration at its new sequencing centre in Shanghai." It's a promising approach, he adds, but he notes that no one yet knows how successful it will be.

The genetic approach has delivered encouraging results for a five-year, $€ 20$-million (US\$27-million) public-private partnership called NEWMEDS, launched in 2009 by the European Commission to speed the development of treatments for schizophrenia and depression. NEWMEDS coordinator Tine Bryan Stensbøl, director of research at the Danish pharmaceutical company H. Lundbeck in Valby, says that scientists in the consortium have used genome information collected from the Icelandic population by the Reykjavik-based genetics company deCODE to identify a copy number variant that they believe will be important in understanding the pathology of schizophrenia. The commission has awarded NEWMEDS a €1-million top-up to investigate further.

Lundbeck is a medium-sized company that remains committed to drug discovery in psychiatric disease. It has, for example, just signed an agreement worth more than a billion dollars with the Japanese company Otsuka Pharmaceutical to develop and market products for mental disorders. "We are certain that the rewards will come and I'm glad we will be well-placed to enjoy them," says Stensbøl. But she regrets that other companies are moving away, as she believes that competition can stimulate the field: "We need a critical mass of companies there when the new targets come."

Johnson \& Johnson is one of the few major international firms keeping the faith. Its head of neuroscience, Husseini Manji, who

\section{$\rightarrow$ NATURE.COM}

See Nature's

schizophrenia

special:

go.nature.com/ctwqay is based in New Jersey, says that "things are cyclical - for those who stay the course, the breakthroughs will finally come".

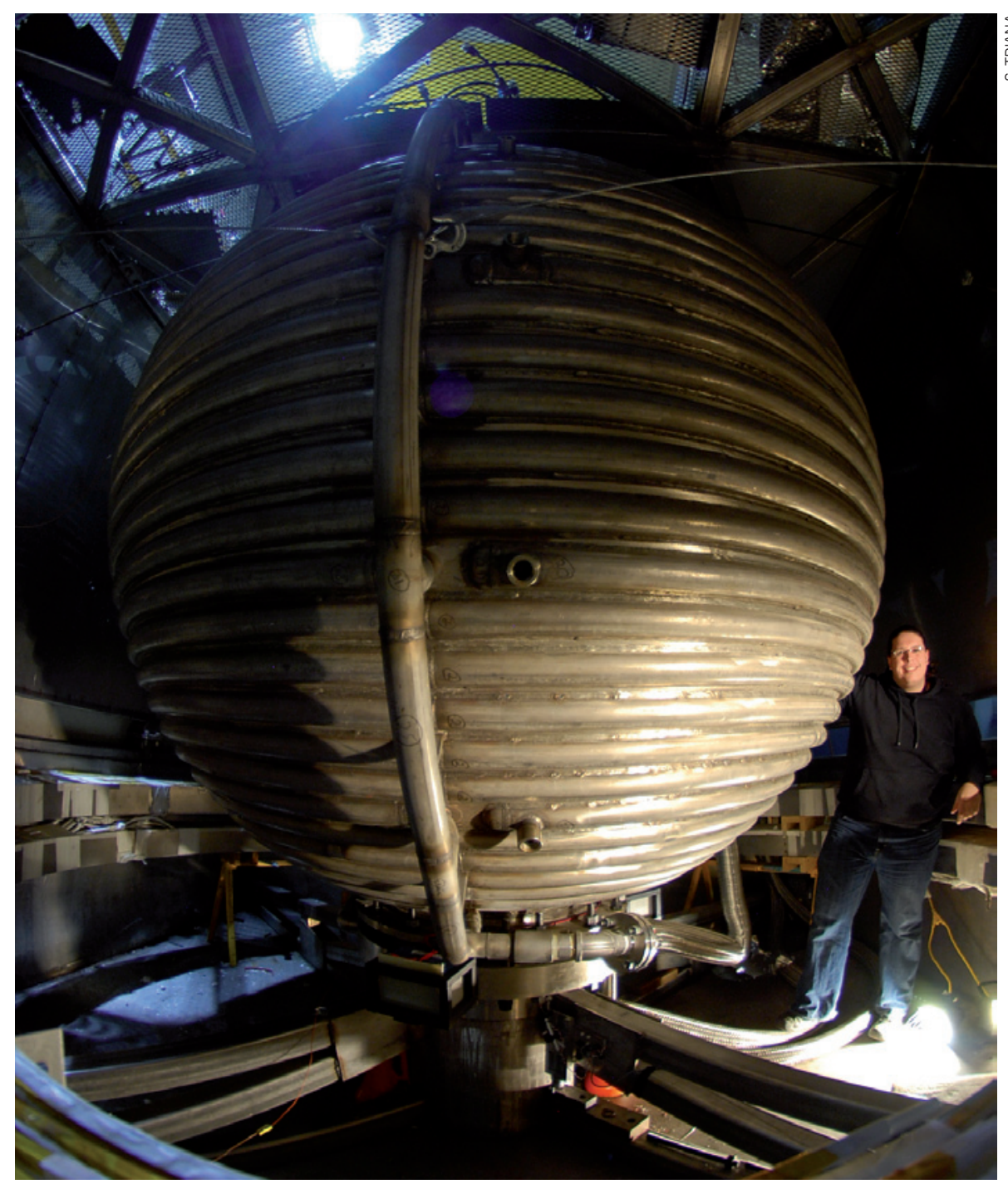

Daniel Zimmerman is part of a team that has been working for ten years to simulate Earth's magnetic field.

\section{EARTH SCIENCE}

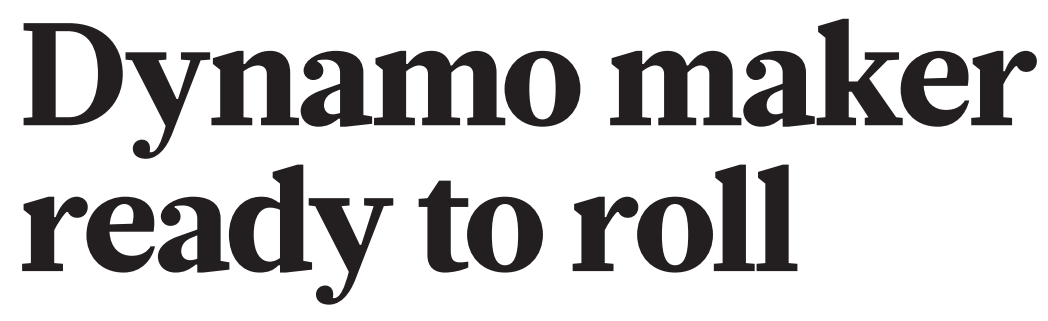

\section{Two rotating spheres separated by thousands of kilograms of liquid sodium aim to mimic Earth's interior.}

\section{BY SUSAN YOUNG}

1 The 3-metre-tall ribbed sphere looks like a 'visitor' from another planet, dramatically lit and encased within a sturdy steel box. In fact, the giant orb, housed in a cavernous warehouse at the University of Maryland, College Park, is meant to approximate Earth's core.

Ten years in the making, the US\$2-million project is nearly ready for its inaugural run.
Early next year, the sphere will begin whirling around while loaded with 13,000 kilograms of molten sodium heated to around $105^{\circ} \mathrm{C}$. Researchers hope that the churning, electrically conducting fluid will generate a selfsustaining electromagnetic field that can be poked, prodded and coaxed for clues about Earth's dynamo, which is generated by the movement of liquid iron in the outer core. If it works, it will be the first time that an 